A. H. Xox

ГУ «Научно-практический иентр Государственного

комитета судебных экспертиз Республики Беларусь»

A. Khokh

Scientific and Applied Center of the State Committee

of Forensic Examination of the Republic of Belarus

М. В. Ермохин, кандидат биологических наук

ГНУ «Институт экспериментальной

ботаники им. В. Ф. Купревича НАН Беларуси»

M. Ermokhin, Ph.D in Biological Sciences

Kuprevich Institute of Experimental Botany

of The National Academy of Sciences of Belarus

\title{
УСТАНОВЛЕНИЕ МЕСТА ПРОИСХОЖДЕНИЯ ЛЕСОМАТЕРИАЛОВ ИЗ ДРЕВЕСИНЫ СОСНЫ ДЕНДРОХРОНОЛОГИЧЕСКИМ МЕТОДОМ
}

\author{
THE DETERMINATION OF PINE TIMBER PLACE OF ORIGIN \\ BY USING DENDROCHRONOLOGICAL METHOD
}

\begin{abstract}
Цель статьи - предложить поэтапный алгоритм решения задачи, связанной с установлением местопроизрастания срубленной древесины на примере сосны обыкновенной (Pinus silvestris L.) - самой распространенной лесообразующей древесной породы в Республике Беларусь и наиболее частого объекта экологических правонарушений, в том числе нарушений лесного законодательства. Отмечается, что данная задача успешно решается в рамках судебно-ботанической экспертизы благодаря ее техническим, научно-методическим и другим возможностям. При этом применен, учитывая сложность получения информации о месте происхождения сосновых лесоматериалов, наиболее точный и доступный инструмент - дендрохронологический метод, который позволяет на основе качественно-количественного анализа дендрологических признаков идентифицируемых экспертных объектов получить достаточно точные результаты. Изложенные современные подходы к решению задачи в рамках судебно-ботанической экспертизы аргументированы и объективны, а полученные данные могут использоваться как справочные или ориентировочные сведения в дендрологических экспертных исследованиях. Являясь важным научно-методическим подспорьем для экспертов, занимающихся проведением судебно-ботанических экспертиз, статья имеет не только теоретическую, но и прежде всего практическую направленность, выраженную в виде примеров, помогающих эксперту более детально освоить изложенную информацию для использования ее при проведении таких экспертиз с помощью дендрологического анализа. Методологическую основу исследования составил диалектико-материалистический подход, который способствовал осознанию процессов и явлений в рамках объекта исследования, в их развитии и взаимосвязи. Во время исследования для решения поставленных задач в комплексе применялись общие и специальные методы, в частности: системно-структурный - для раскрытия сущности исследуемых категорий и правовых явлений и их элементно-компонентного состава; научной абстракции - с целью формирования позиции касательно оценки теоретических, правовых и организационных основ; догматический метод способствовал уточнению понятийно-категориального аппарата исследования; моделирования - формулировке выводов; статистический - обобщению полученных результатов.

Ключевые слова: древесина; сосна обыкновенная; судебно-ботаническая экспертиза; местопроизрастания; незаконные рубки.
\end{abstract}

(c) A. H. Хох, М. В. Ермохин, 2019 
Мета статті - запропонувати поетапний алгоритм вирішення завдання, пов'язаного зі встановленням місцезростання зрубаної деревини на прикладі сосни звичайної (Pinus silvestris L.), що $€$ найпоширенішою деревиною в Республіці Білорусь, яка утворює лісові масиви, і найбільш частим об'єктом екологічних правопорушень, у тому числі порушень лісового законодавства. Зазначається, що це завдання успішно вирішується в межах судово-ботанічної експертизи завдяки ії технічним, науково-методичним та іншим можливостям. При цьому застосований, з огляду на складність отримання інформації про місце походження соснових лісоматеріалів, найбільш точний і доступний інструмент - дендрохронологічний метод, який дає змогу на основі якісно-кількісного аналізу дендрологічних ознак ідентифікованих експертних об'єктів отримати досить точні результати. Викладені сучасні підходи до вирішення завдання в межах судово-ботанічної експертизи аргументовані і об’єктивні, а отримані дані можуть використовуватися як довідкові або орієнтовні відомості в дендрологічних експертних дослідженнях. Як важлива науково-методична підмога для експертів, які провадять судово-ботанічні експертизи, стаття має не тільки теоретичну, а й насамперед практичну спрямованість, виражену у вигляді прикладів, які допомагають експерту більш детально освоїти викладену інформацію для використання їі під час таких експертиз за допомогою дендрологічного аналізу. Методологічну основу дослідження становив діалектико-матеріалістичний підхід, який сприяв розумінню процесів і явищ у межах об'єкта дослідження, у їх розвитку та взаємозв’язку. Під час дослідження для вирішення поставлених завдань у комплексі застосовувалися загальні та спеціальні методи, зокрема: системно-структурний - для з'ясування сутності досліджуваних категорій і правових явищ, їх елементно-компонентного складу; наукової абстракції - з метою формування позиції до оцінки теоретичних, правових та організаційних засад; догматичний метод сприяв уточненню понятійно-категоріального апарату дослідження; моделювання - формулюванню висновків; статистичний - узагальненню отриманих результатів.

Ключові слова: деревина; сосна звичайна; судово-ботанічна експертиза; місцезростання; незаконні рубки.

The purpose of the article is to propose a step-by-step algorithm for solving the problem of determining the place of growth of felled wood on example of Scots Pine (Pinus silvestris L.), the most common forest-forming species of wood in the Republic of Belarus and the most common object of environmental violations, including violations of forest legislation. It is noted that this problem is being successfully solved within the framework of the forensic botanical examination due to its technical, scientific, methodological and other capabilities. Moreover, taking into account the complexity of obtaining information about the place of origin of pine timber, the most accurate and affordable tool is used - the dendrochronological method, which allows obtaining fairly accurate results based on the qualitative and quantitative analysis of dendrological features of identified expert objects. The outlined modern approaches to solve the problem within the framework of the forensic botanical examination are reasoned and objective, and the obtained data can be used as reference or indicative information in dendrological expert studies. Being an important scientific and methodological tool for experts involved in forensic botanical examinations, the article has not only theoretical, but primarily also practical focus, expressed in the form of examples that help the expert to more thoroughly study the presented information in order to use it while conducting such examinations trough dendrological analysis. The methodological basis of the study was the dialectical-materialistic approach, which contributed to the awareness of processes and phenomena within the framework of the object of study, in their development and interconnection. During the study, to solve the set tasks, general and special methods were complexly used, in particular: systematic and structural - to reveal the essence of the studied categories and legal phenomena and their elemental-component composition; scientific abstraction - aiming to form a position regarding the assessment of theoretical, legal and organizational foundations; the dogmatic method contributed to the refinement of the conceptual and categorical apparatus of research; modeling - formulation of conclusions; statistical - to a generalization of the results.

Keywords: wood; Scots Pine; forensic botanical examination; habitat; illegal felling.

В Республике Беларусь леса занимают почти 40 \% территории. Самой распространенной древесной породой является сосна обыкновенная (Pinus sylvestris L.); она же и наиболее частый объект противоправных действий, связанных с незаконной рубкой леса и оборотом древесины. При расследовании правонарушений данной категории в ряде случаев возникает необходимость в получении информации о месте происхождения сосновых лесоматериалов. Наиболее точным и доступным инструментом для решения этой сложной эксперт- 
ной задачи является дендрохронологический метод, поскольку годичные кольца древесных растений как природная регистрирующая структура служат ценным источником информации, отражающей локальные и глобальные изменения окружающей среды.

Разные аспекты проведения дендрологических исследований нашли отражение в трудах А. П. Ермакова, Б. А. Колчина, Д. Е. Кузменкова, Д. С. Малоквасова, А. А. Маслова, А. Н. Оркина, С. Б. Пальчикова, М. И. Попковой, Е. А. Прохоровой, М. И. Розанова, Д. Е. Румянцева, И. И. Тычкова, Н. Б. Черных, В. В. Шишова и др. Дендрохронологический анализ имеет сегодня развитую научно-методическую и математическую базу, а его точность и достоверность, по мнению отечественных и зарубежных специалистов (Orkin, \& Malokvasov, 1992; Rozanov, 1971), считается достаточной для решения экспертных задач при проведении судебно-ботанических экспертиз. Создание литературы, в которой бы в доступной форме был описан алгоритм проведения исследований, позволяющих определить место происхождения лесоматериалов на примере сосны обыкновенной, наилучшим образом дополнит весомые результаты ученых.

Основу судебно-экспертного исследования лесоматериалов из древесины сосны дендрохронологическим методом составляют лабораторные исследования, статистическая обработка и анализ полученной дендрохронологической информации. При этом видовая принадлежность устанавливается на основании комплекса макроскопических показателей, позволяющих визуально, без применения приборов либо с помощью лупы или стереоскопического микроскопа при увеличении 8-16× в отраженном свете, идентифицировать вид древесного растения по следующим параметрам:

цвет и структура коры;

цвет древесины на торцах;

наличие ядра, ширина заболони и степень резкости перехода от ядра к заболони;

степень видимости годичных колец и их очертания;

четкость границы между ранней и поздней древесиной в годичных кольцах;

наличие и количество смоляных ходов, их размеры.

Если невозможно определить видовую принадлежность на основании комплекса макроскопических показателей, она определяется по анатомическим признакам сравнением с эталонными образцами (натурная коллекция), а в случае их отсутствия - по описанию (различные определители древесных пород) (Chavchavadze, 1979; IatcenkoKhmelevskii, Vikhrov, Gzyrian, \& Moskaleva, 1954).

Пробоподготовку дендрохронологических образцов можно проводить обрезкой (для кернов) и шлифовкой (для спилов и фрагментов). Независимо от выбранного варианта пробоподготовки важно добиться максимально ровной их поверхности, избежать образования царапин и других изъянов на обрабатываемой поверхности (Khozkh, Kuzmenkov, Prokhorova, \& Ermokhin, 2018).

Замеры параметров радиального прироста древесины проводят по отсканированным изображениям, начиная с внешнего (или первого от периферии) годичного кольца по направлению к сердцевине строго перпендикулярно границам годичных колец. Для каждого экспертного объекта (далее - ЭО) должно быть получено от двух до восьми серий годичных колец (в зависимости от сложности и объема работ).

После получения результатов измерений для каждого ЭО проводится устранение ошибок, которые обнаруживаются при визуальном сравнении графиков изменчивости ширины годичного кольца (далее - ШГК) между двумя сериями годичных колец из одного образца древесины (например, необычно широкое или узкое годичное кольцо в от- 
дельном образце). Далее для каждого образца по каждому году рассчитывается среднее арифметическое этого параметра.

До решения вопроса о местопроизрастании следует убедиться, на одном или на разных локальных участках произрастали ЭО. Для этого проводят оценку взаимосвязи между сравниваемыми древесно-кольцевыми хронологиями (далее - ДКХ), основываясь на результатах расчетов парных коэффициентов корреляции Пирсона $(r)$ и коэффициентов синхронности $(\mathrm{Kc})$ между каждой парой образцов. Исходя из их абсолютного значения определяют связь между ЭО согласно установленным зависимостям (табл. 1).

Таблица 1

\section{Основные статистические показатели, используемые} при сопоставлении ЭО

\begin{tabular}{c|c|c|c}
\hline$r$ & $\mathrm{~K}_{c}$ & Сила связи & Интерпретация \\
\hline$>0,80$ & $>90$ & Сильная & Характерно для ЭО из одного дерева \\
\hline$\geq 0,50$ & $\geq 80$ & Умеренная & $\begin{array}{c}\text { Характерно для ЭО из деревьев, растущих } \\
\text { на одном и том же участке местности }\end{array}$ \\
\hline$\leq 0,50$ & $\leq 60$ & Слабая & $\begin{array}{c}\text { Характерно для ЭО из деревьев, условия } \\
\text { местопроизрастания которых различны }\end{array}$
\end{tabular}

Далее проводят кластерный анализ с целью объединения сравниваемых образцов в группы, обладающие сходными характеристиками, - кластеры. Например, на дендрограмме (см. рис.) можно уверенно выделить два кластера: I образован ДКХ № 4, II - ДКХ № 1-3.

Проверка качества проведенных измерений осуществляется в программе COFECHA из пакета DPL (Dendrochronology Program Library), которая преобразо-

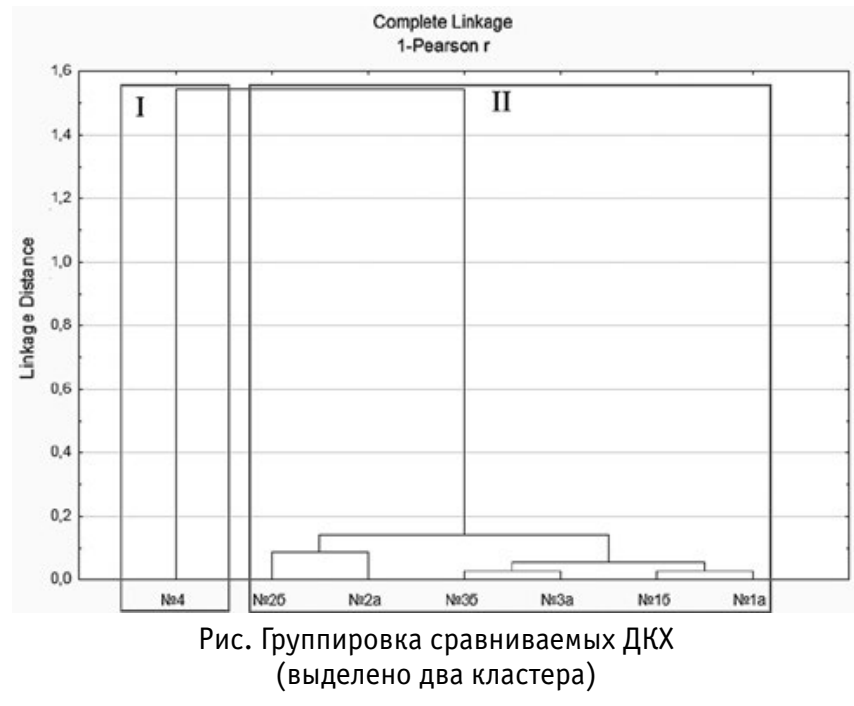
вывает серии годичных колец с помощью короткого кубического сплайна, а затем сравнивает все полученные серии между собой и выявляет проблемные участки. В итоговом отчете программы анализируют следующие параметры. В части 5 - значения коэффициентов корреляций между сегментами (в случае очень низких значений (менее 0,32 ) целесообразно перепроверить данные участки «проблемных» хронологий). В части 6 для каждого сегмента серии программа рассчитывает вероятность возникновения ошибки и находит возможную причину ее возникновения, обозначая ее соответствующей буквой латинского алфавита (например, [D] означает отсутствующие кольца (нулевые значения), [E] - значения, которые являются статистическими выбросами от среднего значения за год). В части 7 оценивают коэффициент корреляции усредненной ДКХ, 
который не должен опускаться ниже установленного (в зависимости от выбранной длины сегмента рекомендуемый уровень 50 лет).

После проверки качества измерений проводят стандартизацию ДКХ. Изменчивость радиального прироста стандартизируют отдельно для каждого ЭО с дальнейшим усреднением индексов и построением стандартизированной хронологии.

Для каждого ЭО подбирают индивидуальную биологическую кривую роста, а индексы рассчитывают путем деления значений ширины годичного кольца из соответствующих значений аппроксимирующей кривой:

$$
I t=R t / G t,
$$

где: $I t$ - индекс ширины годичного кольца в год $t$;

$R t$ - фактическая ширина годичного кольца в год $t$;

$G t$-ширина годичного кольца по аппроксимирующей кривой в год $t$.

После этого следует оценить почвенно-грунтовые условия произрастания дерева и тип древостоя.

Тип древостоя (одновозрастный или разновозрастный) устанавливают исходя из возраста (для целей исследования - количества годичных колец) каждого ЭО. Если разбежка составляет не более 20 лет, то ЭО относится к одновозрастному типу древостоя, если более 20 лет - к разновозрастному.

Возможные условия произрастания дерева (богатство почвы, режим увлажнения) оценивают по форме ДКХ - если местопроизрастания не установлено.

Информация о типе древостоя необходима для того, чтобы минимизировать погрешности при построении усредненной ДКХ по ЭО и правильно провести их стандартизацию, а об условиях произрастания дерева - чтобы в дальнейшем подобрать правильные контрольные ДКХ.

Дифференцировать ДКХ можно по их групповым свойствам. Для Республики Беларусь выделяют три группы древесно-кольцевых хронологий:

1) сосняки на почвах неустойчивого и нормального увлажнения (сосняки лишайниковые, брусничные, вересковые, мшистые, орляковые, кисличные и свежие черничные);

2) сосняки на почвах избыточного увлажнения (сосняки багульниковые и долгомошные);

3) сосняки на верховых болотах (осоково-сфагновые и сфагновые).

Основным показателем, с помощью которого можно охарактеризовать условия произрастания дерева и провести их дифференциацию, является значение среднеквадратического отклонения в стандартизированных сериях годичных колец (находится в разделе «standard chronology statistics» выходного файла программы ARSTAN с расширением «_out»).

Еще один косвенный показатель характеристики условий произрастания - автокорреляционная составляющая, связанная с влиянием экологических условий предыдущих лет на прирост текущего года. Так, у деревьев из первой и второй групп отмечается значимая высокая автокорреляция только первого и второго порядка, а у деревьев третьей группы в годичном приросте существенное влияние оказывают экологические условия как минимум четырех предыдущих лет.

Значения автокорреляций находятся в разделе «standard chronology statistics» - «autoregression coefficients» выходного файла программы ARSTAN с расширением «_out». 
Степень влияния внешних экологических факторов оценивается коэффициентом чувствительности, который рассчитывается по формуле (Fritts, 1976):

$$
\mathrm{K}_{r}=\frac{1}{n-1} \sum_{t=1}^{t=n-1}\left(\frac{2\left(x_{t+1}-x_{t}\right)}{x_{t+1}+x_{t}}\right)
$$

где: $x$ - ширина годичного кольца или индекс прироста за год $t$;

$n$ - протяженность ряда (количество лет).

Пороговые значения описанных выше показателей приведены в таблице 2.

Таблица 2

\section{Основные показатели, используемые для дифференциации условий произрастания ЭО}

\begin{tabular}{c|c|c|c|c}
\hline $\begin{array}{c}\text { Стандартизиро- } \\
\text { ванные ДКХ }\end{array}$ & $\begin{array}{c}\text { Среднеквадратичное } \\
\text { отклонение }\end{array}$ & $\begin{array}{c}\text { Значимая } \\
\text { автокорреляция }\end{array}$ & $\begin{array}{c}\text { Коэффициент } \\
\text { чувствительности }\end{array}$ & $\begin{array}{c}\text { Средняя ШГК } \\
\text { возрасте } \\
100 \text { лет, мм }\end{array}$ \\
\hline Группа 1 & $<0,20$ & 1 порядка & $0,10-0,20$ & $0,7-1,2$ \\
\hline Группа 2 & $0,21-0,35$ & 1 и 2 порядка & $0,15-0,25$ & $0,5-0,7$ \\
\hline Группа 3 & $>0,35$ & 1 и более порядков & $>0,25$ & $0,3-0,5$
\end{tabular}

Для поиска максимально схожей с ЭО контрольной ДКХ также проводят кластерный анализ и рассчитывают коэффициенты корреляции и синхронности. В результате получают ранжированный ряд значений коэффициентов корреляции и синхронности между тестовой хронологией и контрольными шкалами (ранг 1 имеет контрольная шкала с максимальным значением коэффициента корреляции). В данном ранжированном ряду отбирают три первых ранга и соответственно три возможных варианта места происхождения древесины.

Контрольные ДКХ могут считаться подходящими в том случае, если коэффициент корреляции составляет не менее 0,4 , а коэффициент синхронности не менее 0,6.

После подбора контрольных шкал проводят детальное сравнение графиков ДКХ ЭО и ДКХ данной древесной породы, в данном географическом регионе, в местопроизрастании определенного типа, при определенном типе древостоя (одновозрастном, разновозрастном) по таким двум позициям:

общее сходство возрастных кривых;

сравнение погодичных колебаний.

Обычно сочетание визуального анализа трех отобранных графиков с анализом значений коэффициентов корреляции и синхронности позволяет установить наиболее вероятное место происхождения древесины с точностью до одного варианта.

Вывод о том, что сравниваемая ДКХ ЭО и контрольная ДКХ имеют общее происхождение, базируется на совпадении общей формы кривых, а также реперных лет (периодов резких угнетений и кульминаций прироста). В противном случае (при несовпадении) в заключении указывают, что объекты имеют различное происхождение.

Следует отметить, что полного геометрического совпадения формы серий годичных колец у разных деревьев не бывает. Это обусловлено тем, что изменение внешних условий для каждого дерева индивидуально, поэтому и степень ответных реакций древесных 
организмов различна. Соответственно неизбежны расхождения в слабовыраженных реперных годах. Критерием календарной сопряженности служит сходство в повторяемости экстремальных значений (периодов угнетений) в сериях годичных колец.

По результатам сравнительного исследования эксперт дает качественно-количественную оценку соответствующих показателей, свидетельствующих об их сходстве / отличии.

При оценке различающихся признаков определяют их существенность и степень влияния на вывод о принадлежности или непринадлежности к определенному участку местности.

На основе оценки результатов исследования эксперт формулирует один из следующих выводов.

Вывод о принадлежности представленных на исследование образиов древесины конкретному местопроизрастанию (конкретному выделу) формулируется исходя из совокупности измеряемых и анализируемых признаков, в том числе на основе:

установления общей формы сравниваемых ДКХ (контрольной из базы данных и контрольной, построенной по образцам сравнения);

установления совпадения реперных лет ДКХ ЭО и контрольной ДКХ по образцам сравнения не менее чем в 90 и 80 \% случаев соответственно;

значения коэффициента корреляции не менее 0,7 ;

значения коэффициента синхронности не менее 0,8 .

Пример вывода эксперта: «Образцы древесины сосны обыкновенной получены из деревьев, произраставших на территории ... лесхоза ... лесничества ... лесного квартала».

Вывод о принадлежности представленных на исследование образцов древесины определенной территории (площадью км$^{2}$ ) формулируется исходя из совокупности измеряемых и анализируемых признаков, в том числе на основе:

установления общей формы сравниваемых ДКХ (контрольной из базы данных и контрольной, построенной по образцам сравнения);

установления совпадения реперных лет ДКХ ЭО и контрольной ДКХ по образцам сравнения не менее чем в 90 и 80 \% случаев соответственно;

значения коэффициента корреляции не менее 0,5 ;

значения коэффициента синхронности не менее 0,6 .

Пример вывода эксперта: «Представленные на исследование образцы древесины сосны обыкновенной получены из деревьев, произраставших на территории ... района ... области в регионе площадью чает следующие лесхозы: квадратных километров. Данная территория вклю-

Вывод «решить вопрос не представляется возможным» формулируется экспертом с обязательным объяснением причин, которые не позволяют ответить на вопрос, поставленный на разрешение экспертизы, например «недостаточное количество экспертных объектов (менее 3-х), не позволяющее выявить достаточно полный комплекс дендрохронологических показателей и построить достоверную ДКХ».

В случае если в ходе исследования не удалось установить местопроизрастания данного на исследование объекта, необходимо делать вывод о том, что лесоматериалы были заготовлены за пределами Республики Беларусь.

Если на разрешение экспертизы вынесены вопросы, выходящие за пределы специальных знаний эксперта, предоставленные ему материалы недостаточны для дачи 
заключения и не могут быть восполнены, составляется мотивированное сообщение о невозможности дачи заключения.

Bbıоды. Представленный в статье алгоритм решения задачи по установлению места происхождения лесоматериалов из древесины сосны обыкновенной путем проведения дендрологических исследований методом с конкретными примерами экспертных выводов является важным научно-методическим подспорьем для экспертов, занимающихся проведением судебно-ботанической экспертизы.

\section{References}

Chavchavadze, E. S. (1979). Drevesina khvoinykh. Morfologicheskie osobennosti, diagnosticheskoe znachenie. L.: Nauka. Leningr. otd-nie. $191 \mathrm{s.}$

Fritts, H. C. (1976). Tree rings and climate. London: Academic press. $576 \mathrm{p}$.

Iatcenko-Khmelevskii, A. A. Vikhrov, V. E., Gzyrian, M. S., \& Moskaleva, V. E. (1954). Osnovy i metody anatomicheskogo issledovaniia drevesiny. L.: Izdatelstvo AN SSSR. $337 \mathrm{s.}$

Khokh, A. N., Kuzmenkov, D. E., Prokhorova, E. A., \& Ermokhin, M. V. (2018). Metodicheskie rekomendatcii po issledovaniiu lesomaterialov dendrokhronologicheskim metodom $v$ sudebno-botanicheskoi ekspertize / NPTc Gos. kom. sudeb. ekspertiz Resp. Belarus. Minsk: Pravo i ekonomika. 46 s.

Orkin, A. N., \& Malokvasov, D. S. (1992). Sudebnaia dendrokhronologiia: ucheb. posobie. Khabarovsk: Vysshaia shk. MVD RF. $34 \mathrm{s.}$

Rozanov, M. I. (1971). Dendrokhronologicheskie metody ekspertizy drevesiny. Ekspertnaia tekhnika. M.: VNIISE. Vyp. 34. S. 45-65.

\section{Список использованных источников}

Чавчавадзе, Е. С. (1979). Древесина хвойных. Морфологические особенности, диагностическое значение. Л.: Наука. Ленингр. отд-ние. 191 с.

Fritts, H. C. (1976). Tree rings and climate. London: Academic press. 576 p.

Яценко-Хмелевский, А. А., Вихров, В. Е., Гзырян, М. С., \& Москалева, В. Е. (1954). Основы и методы анатомического исследования древесины. Л.: Издательство АН СССР. 337 с.

Хох, А. Н., Кузменков, Д. Е., Прохорова, Е. А., \& Ермохин, М. В. (2018). Методические рекомендации по исследованию тесоматериалов дендрохронологическим методом в судебно-ботанической экспертизе / НПЦ Гос. ком. судеб. экспертиз Респ. Беларусь. Минск: Право и экономика. 46 с.

Оркин, А. Н., \& Малоквасов, Д. С. (1992). Судебная дендрохронология: учеб. пособие. Хабаровск: Высшая шк. МВД РФ. 34 с.

Розанов, М. И. (1971). Дендрохронологические методы экспертизы древесины. Экспертная техника. М.: ВНИИСЭ. Вып. 34. С. 45-65. 